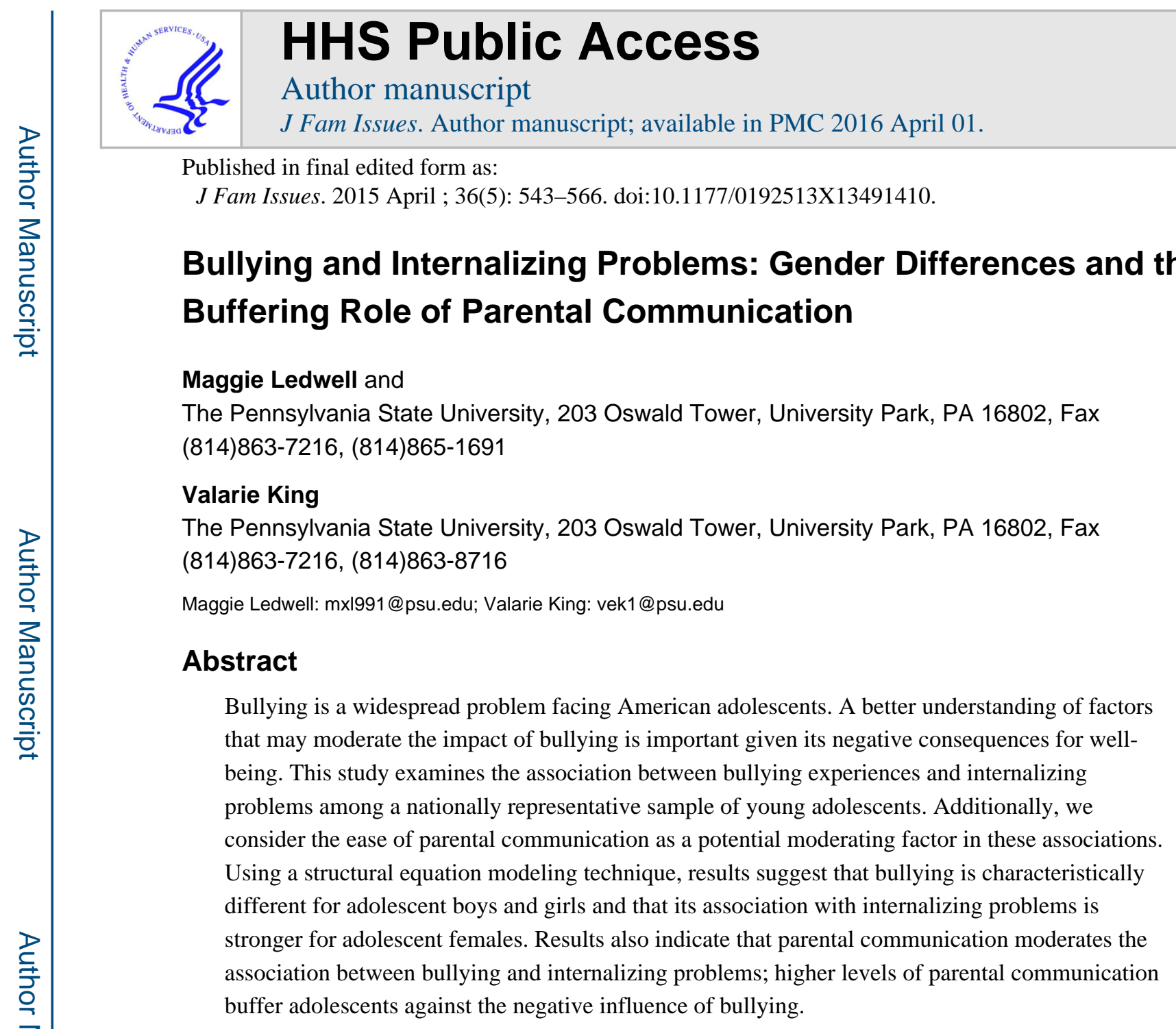

\title{
Keywords
}

bullying; adolescence; internalizing problems; parental communication; gender

Bullying is a widespread problem in contemporary American schools. According to a report from the U.S. Department of Education, over 7 million US students ages 12 to 18, or $28 \%$ of such students, reported being bullied at school during the 2008/2009 school year (DeVoe \& Murphy, 2011). Given previous findings on the negative consequences of bullying for adolescent well-being (Nansel et al., 2001) and the potential long-term effects, it is important to identify factors that may help buffer young adolescents who are bullied from these negative psychosocial consequences. One such potentially important factor is the role of parents, who along with peers can play an important role in adolescent development. Little research, however, has explored the buffering role of parents against the negative effects of bullying experiences.

This study examines how experiencing bullying affects young adolescents' internalizing behavior. Developmental research regards internalizing problems (e.g. depression and psychological distress) to be a key dimension of adjustment and wellbeing (Achenback \& McConaughy, 1997). Gender differences in the experience of bullying, as well as its 
association with well-being, are explored. Additionally, this study examines how supportive parental relationships, specifically high levels of parental communication, with these young adolescents might moderate the effect of bullying on internalizing problems. A structural equation modeling approach with data from the Health Behavior in School-Aged Children (HBSC) 2001-2002 cross-sectional survey is used to examine these aspects of adolescent bullying experiences.

\section{Bullying in Adolescence}

Peer victimization, or bullying, is commonly defined as a specific type of aggressive behavior which is repeated over time with the intention to harm or disturb another. This behavior is characterized by an asymmetrical distribution of power, in which a more powerful individual or group of individuals go after a weaker person (Olweus, 1978; 2001). Bullying is social in nature, where the acts of bullying relate to the group dynamics in which it takes place (Arora, 1996). Bullying behavior takes on three distinct forms, physical, verbal, and relational aggression, which may be direct or indirect in nature.

A number of studies point to gender differences in the experience of different forms of victimization; boys are more likely to fall victim to physical aggression, while girls are more likely to be the victims of relational bullying (e.g. Crick \& Grotpeter, 1995; Crick et al., 1999). While research has shed light on the qualitatively different experiences of bullying for adolescent boys and girls, very little research has tested whether there are gender differences in the impact of bullying on adolescent well-being (Paquette \& Underwood, 1999), with greater focus on differences in externalizing behavior (e.g. Lamarche et al, 2007). The current study tests for gender differences in both the experience of bullying as well as the consequences for internalizing behavior. We hypothesize that bullying will exert a stronger negative impact on the internalizing behavior of adolescent females compared to males because of gender differences in the nature and importance of social relations with peers during adolescence and the potential for greater interpersonal vulnerability among females. The individual experience, as well as the broader culture, of adolescence is strongly shaped by gender (Perry \& Pauletti, 2011; Eder, Evans \& Parker, 1995). The strong emphasis placed on friendships by adolescent females may contribute to greater concerns over social approval and status, and in turn greater internalization of problems when peer relations are perceived to be in jeopardy (Leadbeater, Kuperminc, Blatt \& Hertzog, 1999; Rose \& Rudolph, 2006). Additionally, beginning in adolescence internalizing problems such as depression become more prevalent among females compared to males (Leadbeater et al, 1999).

Adolescents who fall victim to bullying often experience higher rates of psychosocial problems than their uninvolved peers (see Hawker and Boulton 2000 for a review). Prior research on the psychosocial impact of peer victimization has had one or more notable weaknesses that have limited our current understanding in this area, including reliance on generic measures of bullying (e.g. Holt \& Espelage 2007; Spriggs, Iannotti, Nansel \& Haynie, 2007) or individual indicators of bullying sub-types rather than multi-dimensional measures (e.g. Wang, Iannotti \& Nansel, 2009), and few considerations of gender differences in the impact of bullying experiences on internalizing problems (e.g. Nansel et 
al., 2001). The current study includes multiple measures of bullying (physical, verbal and relational) as a latent construct; such measurement captures the multidimensionality of bullying and the likely comorbid experiences of bullying types, which may act together to shape internalizing problems. The measurement of bullying as a multidimensional construct is an improvement over generic measures of bullying which may underestimate both the prevalence of victimization and the pervasiveness of its influence on mental health outcomes (Esbensen \& Carson, 2009). Additionally, consideration is given to gender differences in experiences in the measurement of the bullying construct. Finally, the current study explicitly tests for gender differences in the impact of bullying on internalizing problems.

\section{Influence of Parents}

While adolescence is often viewed as a period of increased individuation and autonomy, the parent-child bond remains important and the significance of parent-child cohesiveness endures (Newman, 1989). Children who have more positive and supportive relationships with their parents tend to fare better socially, emotionally, and psychologically than those who lack a supportive parental bond (Masten \& Coatsworth, 1998). Various aspects of the parental relationship are associated with psychosocial wellbeing in adolescence. For example, greater parental support is positively associated with social competence and negatively associated with adolescent depression (Barber, Stolz \& Olsen, 2005), parental care coupled with low parental indifference is associated with lower prevalence of depression among adolescents (Lui, 2003), and perceived parental support is positively associated with adolescent self-esteem (Lui, 2003). Parental communication, as one aspect of parental support, may also help foster healthy adolescent development. Adolescents whose relationship with their parents is characterized by open and supportive communication are less likely to have a high level of behavioral and emotional problems (Moore, Chalk, Scarpa \& Vandivere, 2002). Open communication with parents may nurture support-seeking behavior and greater coping aptitude (Gentzler, Contreras-Grau, Kerns \& Weimer, 2005). Adolescents' perception of the openness of communication with their parents is also important for their psychological well-being (Hartos \& Power, 1997; Ackard, Neumark-Sztainer, Story \& Perry, 2006). Social support in the form of the perceived availability of responsive interpersonal resources, such as adolescents' perceptions of their ability to talk with their parents, may help to buffer individuals from the potentially harmful effects of stressful experiences, such as bullying (Cohen \& Wills, 1985).

Given that parental support helps to promote healthy psychosocial adjustment in adolescence, we might expect that a positive parent-child relationship could work to buffer the negative effects of peer victimization on adolescent mental-health and well-being. Studies have found that higher levels of parental support are associated with lower odds of peer victimization (Wang et al., 2009; Baldry \& Farrington, 2005) and parent-child communication is negatively associated with experiences of bullying behavior, as either a victim or a bully (Spriggs et al., 2007). To the best of our knowledge, however, no studies have looked at how parental communication may temper the influence of bullying on maladjustment. We hypothesize that the adolescent's level of parental communication will moderate the association between bullying and internalizing problems; that is, the strength of the association will vary as a function of level of parental communication, such that the 
association between bullying and internalizing problems will be stronger when parental communication is low and weaker when parental communication is high.

A few studies have looked at the moderating effects of parental support on the psychosocial maladjustment of bullied adolescents (Bowes, Maughan, Caspi, Moffit \& Arsenault, 2010; Davidson \& Demaray, 2007; Holt \& Espelage, 2007); however the impact of parental communication specifically has not been explored. Additionally, these few studies do not use samples that are nationally representative of the United States. The studies find that the association between bullying and psychosocial distress is significantly weaker among adolescents with more supportive parental relationships, although Davidson \& Demaray (2007) only find this interaction significant for females.

\section{Methods}

\section{Study Population}

The Health Behavior in School-Aged Children (HBSC) Survey is a multinational, schoolbased, cross-sectional survey of adolescents in grades 6 through 10. The World Health Organization (WHO) Regional Office for Europe has sponsored this cross-national survey of health-related behaviors and attitudes, conducting independent surveys in participating countries every four years since the 1985-1986 school year. The U.S. survey utilized in this study was a nationally representative sample of children in grades 6 through 10 during the 2001/2002 school year.

The HBSC study employed a three-stage cluster design. The first stage of the clustering, the primary-sampling unit (PSU), was the school district, the second stage was the school, and the final stage was the classroom. The unit of observation was the individual student. The universe consisted of public, Catholic, and other private school students in grades 6,7,8,9, and 10 in the 50 states and the District of Columbia. Agreement to participate among the original sampling frame of schools yielded a participation rate of 73.2 percent. Within the participating schools, 15,245 students participated out of the 18,620 eligible students, yielding a student response rate of 81.9 percent. Responding students were excluded from the final sample if they were outside of the sample target age range for their grade (outside of the $1-99^{\text {th }}$ percentile for a grade; $n=365$ students), if either grade or age were unknown ( $n=6$ students) or if they were missing on a significant number of "key" variables, specified according to international HBSC protocol $(n=57)$. After the exclusion of these cases, the final sample consisted of 14,817 US students in grades 6 through 10. Data were collected using self-administered, anonymous surveys in classrooms. (See Currie et al, 2004, for more details).

The analytic sample for this study included all adolescents with at least one living parent (biological or step-parent) that they primarily resided with $(n=14,039)$. The sample size for the multi-group models testing the moderating effect of parental communication was reduced to 13,267 after excluding adolescents who provided no information on the quality of communication with their parents. 


\section{Data Analytic Strategies}

Data analyses were conducted in Mplus version 6 in order to adjust for the complex survey design of the HBSC when executing structural equation modeling with latent variables and multigroup analysis (Muthén \& Muthén, 2010). A full-information maximum-likelihood (FIML) technique was utilized to handle missing data. FIML is a maximum likelihood estimation approach that minimizes bias in estimation due to missing data while utilizing all available data in parameter estimation (Enders \& Bandalos, 2001). Results for the structural equation models are based on unweighted data, with adjustments made for sample design. When adjustments were made to the models through weighting, similar results were obtained. The measurement model was first examined using factor analyses to determine how well the hypothesized latent constructs fit the data, with several goodness-of-fit indices used to determine the best-fitting model (chi-square, p-value, RMSEA, CFI). The purpose of the measurement model is to determine the best specification of latent variables. A test of measurement-invariance across genders was then employed using a multi-group model to test whether the latent constructs should be measured in the same way for males and females, using several goodness-of-fit indices to determine the best fitting model. The structural model tested the hypothesized relationship between latent constructs, using the measurement determined from the measurement model. Finally, two sets of multi-group models were run to determine whether the hypothesized relationship between latent constructs was statistically different by group membership, gender or level of parental communication and gender. A Satorra-Bentler chi-square difference test was used in all analyses using a multi-group model, which determines whether the difference between the adjusted chi-squares of constrained and unconstrained models is significant (Satorra \& Bentler, 2001). This test statistic adjusts downward the normal theory $\chi^{2}$ generated with standard maximum-likelihood estimation using a correction factor that reflects the degree of kurtosis (Kline, 2011). This statistic better approximates chi-square under conditions of data non-normality and therefore is a more robust test statistic to use when performing difference testing.

\section{Measures}

The means, standard errors and percentages reported for variables in the measurement section are weighted and based on non-missing data.

Bullying is a latent construct, derived from five questions pertaining to adolescents' experience of different forms of bullying behavior. Each question was preceded by a definition of bullying. Students were asked about the frequency with which they experienced five different forms of bullying within the past few months. Physical experiences of bullying were captured by one question asking how often they were "hit, kicked, pushed, shoved around, or locked indoors". Experiences of verbal bullying were captured with two questions, one regarding how often they were "called mean names, was made fun of, or teased in a hurtful way" (Called Names), and another regarding how often "other students made sexual jokes, comments or gestures" at them (Sex Jokes). Relational bullying is captured by two questions, one regarding how often "other students told lies or spread false rumors about me and tried to get others to dislike me" (Rumors) and one regarding how 
often "other students left me out of things on purpose, excluded me from their group of friends, or completely ignored me" (Leftout). Response categories include: $1=$ I have not been bullied in this way in the past couple of months, $2=$ only once or twice, 3=2-3 times a month, 4= about once a week, and 5= several times a week. Exploratory factor analysis revealed that these five indicators form one composite latent factor for the full sample of males and females, with a standardized Cronbach's alpha (a) of 0.83 . Additional analyses testing for measurement invariance between the males and females in the sample are discussed later.

Internalizing problems is a latent construct, created using three survey items measuring aspects of depression, anxiety and life satisfaction. Students were asked how often in the past 6 months they felt "low" (Depression; $x=2.03 \mathrm{SE}=0.00$ ). Similarly, students were asked how often in the past 6 months they felt "nervous" (Anxiety; $x=2.30 \mathrm{SE}=0.02$ ). Responses to these two questions ranged from 1 "rarely/never" to 5 "about once a day". For life satisfaction, students were presented with a Cantril's ladder and asked to rate from 0 to 10 where they felt they stood, in terms of quality of life. This variable was reverse-coded so that higher scores indicate lower life satisfaction (Life satisfaction; $x=2.50 \mathrm{SE}=0.03$ ). Exploratory factor analysis for the full sample of males and females revealed that these three indicators form a single latent factor with a standardized Cronbach's alpha (a) of 0.61.

\section{Parental Communication}

Using information on who lived in the respondent's main household, the primary parent(s) were identified. The quality of communication with every available parent (mother, father, stepmother, stepfather) was measured. Close parent-child relationships, whether step or biological, are shown to have positive benefits for children and are associated with positive outcomes in adolescence (King, 2006). Therefore, it is important to include the quality of adolescents' relationships with their step- as well as their biological parents. Respondents were asked to rate how easy it was for them to talk to specific people (father, mother, stepfather, stepmother) about things that really bothered them. Possible responses included: $1=$ very difficult, $2=$ difficult, $3=$ easy and $4=$ very easy. The highest rating of communication with any parent was taken as the value for communication quality with parents. Finally, these responses were dichotomized into high communication quality (responses of $1=$ easy and very easy) and low communication quality (responses of $0=$ difficult and very difficult). This variable identifies the highest level of communication with a parent available to the adolescent; the level of ease with which they can talk with the parent they feel the most open with. This schema of variable construction, taking the highest value of parental communication and dichotomizing the variable into high and low quality communication has been employed in past studies, although only using the reports on biological parents (e.g. Spriggs et al., 2007). The majority of respondents $(72.4 \%)$ report having "high" communication quality with their parents.

\section{Controls}

The current literature points to several sociodemographic factors that influence both the propensity for adolescents to experience bullying as well as their level of internalizing problems, and therefore serve as important controls in our models. The respondent's age is 
measured in years ( $x=13.43$ years, $S E=0.06$; e.g. Lewinsohn, Hops, Roberts, Seeley \& Andrews, 1993; Nansel et al., 2001). The adolescent's gender is measured with a dummy variable, females (52\%) are coded 1 and males coded as 0 . Respondents were categorized into four racial/ethnic groups: white (reference group; 61\%), black (14.2\%), Hispanic (15.1\%) and other (9.7\%; e.g. Saluja et al., 2004; Spriggs et al., 2007). Five dummy variables indicate the family structure of the adolescent's primary residence: two biological parents (reference category, 61.1\%), biological mother and stepfather (14.2\%), biological father and stepmother (2.6\%), single mother home (18.9\%), and single father home (3.2\%; e.g. Demo \& Acock, 1996; Stevens, De Bourdeaudhuij \& Van Oost 2002). The family affluence scale (FAS) was used as a composite measure of a family's socioeconomic resources (e.g. Goodman, Slap \& Huang, 2003; Wang et al., 2009). This scale placed a respondent's family into one of three categories, low affluence, medium affluence or high affluence, based on their summed responses to four questions ( $x=2.38, S E=0.02$; Boyce, Torsheim, Currie \& Zambon, 2006). Additionally, two aspects of the adolescent's social experiences may influence both their propensity for victimization and their internalizing behavior, thereby confounding the association of interest: social isolation and bullying perpetration. The variable "isolated" is derived from questions asking respondents about the number of close male and female friends they had $(1=$ no close friends, $1.3 \%, 0=$ at least one close friend, 98.7\%; e.g. Boulton, Trueman, Chau, Whitehand \& Amatya, 1999; Mouttapa, Valente, Gallaher, Rohrbach \& Unger, 2004). "Bully others" is a composite scale which captures the greatest frequency of bullying perpetrated by respondents $(x \equiv 1.81, S E=$ 0.02 ), derived from five questions about bullying that are the converse of those used to create the latent variable for bully victimization, with the same five response categories (e.g. e.g. Haynie et al., 2001; Nansel et al., 2001). The highest frequency value of the individual items is taken as the respondent's value on bullying others. (Similar results were obtained when these two controls were excluded from the overall structural model.)

\section{Results}

\section{Prevalence of experiencing bullying}

An examination of the prevalence of bullying experiences among this sample of adolescents indicates that bullying is widespread, a finding that is consistent with existing literature (DeVoe \& Murphy, 2011). Table 1 presents descriptive information on bullying prevalence by subtype and gender. Descriptive results are weighted and based on non-missing data. Statistically significant chi-square tests reveal that boys and girls experience a significantly different rate of each form, as well as any form, of bullying. However, given the large sample size, results of a chi-square test should be interpreted with caution. Overall, forty-six percent of the adolescents reported being uninvolved, not having experienced any of the five types of bullying behavior in the past few months. A greater proportion of boys (48\%) report being uninvolved, and experiencing no form of bullying in the past few months, compared with girls (43\%); past research similarly finds that more girls are victims of bullying than boys (DeVoe \& Murphy, 2011). Twenty-six percent of adolescents reported experiencing at least one form of bullying infrequently, once or twice in the last few months. On the other end of the bullying continuum, $21 \%$ of the adolescents reported experiencing at least one of the forms of bullying at least once to several times a week. Although a smaller percentage of 
boys reported any involvement with bullying compared to girls, a greater percentage of boys experienced bullying more frequently, at least once a week, compared to girls ( $22 \%$ versus $20 \%)$.

Certain bullying behaviors were more common than others. Being called names was the most common bullying experience among all adolescents, with $34 \%$ reporting having experienced name calling at least once or twice in the last few months. Involvement in the different bullying experiences also differed by gender. Rumor-spreading was the most prevalent form of bullying among girls (34\% experienced it at least once or twice in the last few months), while physical bullying was the least prevalent (8\%). Among boys, name calling was the most prevalent bullying experience (36\% experienced it at least once or twice in the last few months), while physical bullying was least prevalent (20\%), but still much higher than it was for girls.

\section{Measurement model}

Factor analysis was employed to assess the fit of the hypothesized latent constructs of bullying and psychosocial maladjustment to the data. The chi-square value, corresponding $p$ value, root-mean square error of approximation (RMSEA), and confirmatory fit index (CFI) were taken as indicators of the overall goodness of fit of the measurement model. The overall fit of the measurement model proved to be satisfactory, with $\chi^{2}(19)=252.01, \mathrm{p}<$. 001, $\mathrm{RMSEA}=0.03$, and CFI $=0.98$.

To ensure that the measurement model fits the data well for both males and females, a multigroup model was used to test for measurement invariance between genders. A model that was left unconstrained so that the latent variables would have factor loadings and intercepts that varied by gender was compared to models that constrained the factor loadings and intercepts of each latent variable separately to be the same for both genders using the Satorra-Bentler chi-square difference test. Additionally, the totally unconstrained model was compared to a fully constrained model, where the factor loadings and intercepts of both latent variables were constrained to be the same across gender. The Satorra-Bentler chisquare test indicated whether the constrained models produced chi-square statistics that were significantly larger than the unconstrained model, and therefore did not fit the data as well. Results indicate that the factor loadings for both of the latent constructs, particularly bullying, are different for males and females (see Table 2). The primary gender difference in factor loadings is for physical bullying, as the latent variable explained more of the variance in physical bullying for boys than for girls (male model: $R^{2}=0.55,55 \%$ of the variance of the physical bullying indicator; female model: $R^{2}=0.29,29 \%$ of the variance of the physical bullying indicator). This finding is consistent with the descriptive statistics presented earlier demonstrating the lower levels of physical bullying and limited variance in this form of bullying among adolescent females, which contributes to its lower factor loading in the latent bullying construct compared to boys. Multi-group analyses suggest that measuring both of these latent constructs separately for each gender results in a better fit of the data compared to when constructs are constrained to be equal for both genders (unconstrained model: $\chi^{2}(38)=259.97, \mathrm{p}<.001$, RMSEA $=0.03, \mathrm{CFI}=0.98$; fully constrained model: $\chi^{2}(56)=1319.12, \mathrm{p}<.001$, RMSEA $\left.=0.06, \mathrm{CFI}=0.91\right)$. Given the 
improvement in fit when the latent constructs are measured separately by gender, these measurement differences are taken into consideration in the structural model.

\section{Structural Model}

Drawing on past empirical research and theoretical concepts, a structural model with latent variables was formulated in which experiencing bullying was hypothesized to affect internalizing behavior. Considering the gender differences outlined in the previous section, the measurement model of the latent constructs were set to vary for males and females, taking into consideration the variation in bullying and internalizing experiences of males and females. Multi-group analysis of the structural model was performed, using a SatorraBentler scaled chi-square difference test (Satorra \& Bentler, 2001).

A multi-group analysis of the structural model, testing for gender differences, suggests that the basic structural model fits the data well for both genders, with satisfactory scores on the goodness-of-fit indices: $\chi^{2}(19)=252.01, p<.001$, RMSEA $=0.03, \mathrm{CFI}=0.98$. When all control variables were included in the structural model, the full structural model continued to fit the data well. Satisfactory scores were maintained for the goodness-of-fit indices: $\chi^{2}(85)=1079.35, p<.001$, RMSEA $=0.03, \mathrm{CFI}=0.96$. Findings for the structural model provide support for the hypothesized relationship between bullying and internalizing problems. Multigroup analyses (Figure 1) indicate that this association between bullying and internalizing problems is statistically significantly stronger for adolescent females compared to males (Satorra-Bentler scaled chi-square test $=17.58, \mathrm{df}=1, \mathrm{p}<.001$ ). Similar results were obtained when the measurement models were constrained to be the same for both genders.

When gender was included in the structural model as a control we found that females are less likely to experience a greater frequency of bullying compared to males. This finding is consistent with current research findings that although a greater proportion of girls experience at least some bullying, boys are more likely to experience high frequencies of bullying, at least once a week (DeVoe \& Murphy, 2011).

Many of the control variables were significantly associated with experiencing bullying, consistent with expectations and existing literature (see results from the full multi-group structural model in the Appendix). Bullying experiences decrease slightly with age among adolescent females and males. Adolescent females from step-family homes are more likely to experience bullying compared to females from a two-biological parent home. No family structure differences in bullying were found for males. Adolescent males from more affluent families are less likely to experience bullying; this association was not statistically significant for females. Results indicate a moderate and significant association between bullying others and experiencing bullying as the victim; the more teen girls and boys bullied others the more likely they were to be bullied themselves. Adolescent males and females who were isolated, who did not have any close friends, were also more likely to experience bullying.

All of the control variables were significantly associated with internalizing problems, even when considered together in a multivariate framework, consistent with expectations and 
existing literature (see results from the full multi-group structural model for males and females in the Appendix). Internalizing problems increased with age. African American adolescents were less likely to experience internalizing problems compared to whites. Female adolescents from more affluent families experienced lower levels of internalizing problems. Adolescents from every "other" family structure arrangement (single-mother household, single-father household, biological mother/step-father household and biological father/step-mother household) had more internalizing problems compared to those adolescents from a two-biological parent family. The more female adolescents bullied others, the greater their internalizing behavior; this association just missed significance at the $\mathrm{p}<0.05$ level for males ( $\mathrm{p}<0.07$ ). Finally, results indicate that adolescent males (but not females) who were socially isolated were more likely to internalize, compared to those who had at least one friend.

\section{Buffering role of Parental Communication}

Multigroup analysis was performed to examine how both level of communication with parent(s) and gender influence the effect of experiencing bullying on internalizing problems. This tests whether statistically significant differences in regression coefficient pathways exist for four groups: females with high levels of parental communication $(n=5,271)$, males with high levels of parental communication $(n=4,892)$, females with low levels of parental communication $(n=1,776)$, and males with low levels of parental communication ( $n=$ 1,328). Again, the Satorra-Bentler scaled chi-square difference test was used to adjust chisquare under conditions of non-normality.

For these analyses the measurement models were not allowed to vary for the four groups, given the difficulty in constraining factor loadings to vary by gender but to be the same by level of parental communication. Furthermore, while constraining the factors to be equal for both genders results in a slightly poorer fit of the measurement model, the relevant fit indices suggest that measuring these latent constructs in the same way for both genders still fits the data relatively well (unconstrained model: $\chi^{2}(38)=259.97, \mathrm{p}<.001$, RMSEA $=$ $0.03, \mathrm{CFI}=0.98$; fully constrained model: $\chi^{2}(56)=1319.12, \mathrm{p}<.001, \mathrm{RMSEA}=0.06, \mathrm{CFI}$ $=0.91$ ). Therefore, analyses exploring the moderating influence of level of parental communication on the association between bullying and internalizing problems utilized the same measurement model for all four groups. As a robustness check, the structural model was run separately for each group, with unique measurement models, and similar results were obtained.

Results from the multi-group analysis indicate that parental communication does act as a "buffer" for adolescent girls and boys; seen in the smaller total effect of bullying among those with high levels of parental communication (see Figure 2). Unstandardized coefficients should be examined when comparing across groups, as standardized coefficients may be misleading (Kline, 2011). Results from the Satorra-Bentler difference test reveal that the relationship between bullying and internalizing is statistically significantly different between the four gender-parent communication groups at the $\mathrm{p}<0.001$ level (SatorraBentler chi-square statistic $=35.83, \mathrm{df}=1, \mathrm{p}<0.001$ ). Adolescents with low levels of 
parental communication do "worse", bullying contributes to greater internalizing problems for them compared to adolescents with high parental communication.

Gender differences in the effect of experiencing bullying on internalizing problems remain. Gender appears to moderate the association between bullying and internalizing behavior to a greater degree than parental communication (females, high communication unstandardized coefficient $b=0.536, \mathrm{p}<.001$; males, high communication $b=0.361, \mathrm{p}<.001$; females, low communication $b=0.553$, $\mathrm{p}<.001$; males, low communication $b=0.393, \mathrm{p}<.001$ ). That is, while differences in the effect of bullying exist between adolescents who had different levels of communication with their parents, the difference in the effect of bullying on internalizing is substantively greater between adolescent males and females.

\section{Discussion}

The present study examines the association between bullying experiences and internalizing behavior among early adolescents, considering potential moderating factors in this association. Specifically, this study explores how both gender and level of parental communication may moderate the association between bullying and internalizing among young adolescents. Findings lend support for the hypotheses that adolescents who experience a greater frequency of bullying also experience greater levels of internalizing problems, corresponding with past research (Hawker \& Boulton, 2000).

Results also point to gender differences in this association; the effect of bullying on internalizing problems is stronger for adolescent girls than for boys. Research suggests that a gendered, differential vulnerability to internalizing problems may exist, in part, due to socialization that encourages greater self-regulation and reactivity to interpersonal concerns among girls compared to boys (Gore, Aseltine \& Colten, 1993; Leadbeater et al., 1999). Socialization practices that place greater emphasis on the importance of interpersonal relations for girls may help to account for gender differences in the influence that negative interpersonal experiences, such as bullying, have on psychosocial outcomes. Research should further explore how gender differences in adolescent peer culture and status hierarchies (Eder, Evans \& Parker 1995) influence gender differences in the association between bullying and internalizing problems.

The current study also extends prior research by looking at the moderating role of parental communication. Results indicate that parental communication moderates the association between bullying and internalizing problems; parental communication buffers against the negative influence of bullying on adolescent internalizing behavior. Findings also indicate that parental communication acts a buffer in the same way for adolescent males and females. This suggests that parental communication may buffer adolescents by acting as a "sounding board"; adolescents who can easily talk with their parents can process negative social experiences with them, and in turn those experiences do not exert as strong of an effect on their internalizing behavior. Future research should explore how parental communication may work to buffer adolescents from the negative effects of bullying. 
While this study contributes to the current understanding of the intersection of family and peer relations in adolescence, several limitations exist. First, future research should utilize longitudinal data to ensure the temporal accuracy in reports of bullying and indicators of internalizing behavior. One should not make causal inferences and explicit statements about directionality given the nature of the data. Prior research utilizing longitudinal designs have found support for the positive relationship between experiencing bullying and internalizing problems, outlined in the structural model (e.g. Olweus 1992; Smokowski \& Kopasz, 2005). Additionally, longitudinal research on another form of victimization, sexual harassment, continued to find an association between victimization and depression, controlling for prior psychological distress (Houle, Staff, Mortimer, Uggen \& Blackstone, 2011). Such longitudinal research designs provide some evidence that we might expect to find a positive relationship between peer victimization and internalizing problems, despite the crosssectional nature of the data. Future data collection efforts should include measures of bullying in order to help facilitate research exploration of the long-term impact of bullying experiences on individual well-being.

Second, the self-reporting of both independent and dependent variables may contribute to shared method variance. That is, aspects of the respondent's disposition or personality traits may influence their judgments about conceptually distinct ideas (e.g. feeling low about oneself and feeling that he/she is bullied by others) and render correlations among constructs inflated (Lorenz, Conger, Simon, Whitbeck \& Elder, 1991). The use of a single-informant is a common limitation in the bullying literature (see Hawker \& Boulton, 2000), and while some studies attempt to deal with this issue through the use of multiple reporters, this is not always appropriate depending on the information one is trying to obtain (e.g. respondents experience of bullying reported on by teachers may miss events that occur both in and outside of the classroom).

Third, the indicators used to construct the latent variable "internalizing problems" are somewhat limited. However, given data limitations, these measures serve as fairly reliable proxy indictors of internalizing behavior. Future research and data collection efforts should attempt to include more detailed measures of bullying experiences and internalizing as well as other types of outcomes in analyses and large-scale surveys in order to explore these associations in greater detail.

Finally, details about the nature and content of communication between parents and children are not known. While the current study considers the ease of such communication, details about content would help illuminate what types of conversations might be most beneficial in buffering against the negative effects of bullying. Further research should explore what aspects of the communication between parents and adolescents are most protective.

The findings from this study have both important research as well as policy implications. The current study extends prior research by highlighting one moderating, protective factor, parental communication in the association between adolescent bullying and internalizing problems. Future research should further explore additional aspects of the parent-child relationship that may act as protective factors. Additionally, this study extends prior research by explicitly testing and finding evidence for gender differences in the effect of bullying on 
the psychological well-being of teens, using a nationally representative sample of adolescents. Knowledge of the differential effect that bullying may have on the psychosocial well-being of adolescent girls and boys may help to inform interventions targeted at youth who are the victims of bullying. For example, interventions targeted at boys may want to focus more on physical bullying while those targeted at girls may want to focus more on the relational aspects of bullying.

Bullying is a common social experience facing a large number of adolescents. Given its association with poorer outcomes, increased attention should be given to research and policy efforts that seek to understand and combat bullying. Bullying has received increased attention in the national media as a social problem with potentially deadly consequences (e.g. Flegenheimer, 2012). The rash of teen suicides attributed, in part, to bullying calls national attention to an "old problem". The important role of parental communication as a buffer against the negative psychosocial consequences of bullying suggests a possible target of intervention efforts. Promoting parent-child communication efforts may result in the nurturance of psychosocial resilience among bullied adolescents. Parents and educators alike may benefit from an increased understanding that parental communication may buffer adolescents from the negative effects of bullying. Additionally, parents and organizations working with young people should consider how both the experience and impact of bullying may differ for teenage boys and girls. While adolescent girls may not suffer physical trauma as often from the types of bullying they most frequently experience, the types of bullying experienced by adolescent girls appears to nevertheless have a strong influence on their psychosocial well-being and should be taken seriously.

\section{Supplementary Material}

Refer to Web version on PubMed Central for supplementary material.

\section{Acknowledgments}

This research was supported by funding from the Eunice Kennedy Shriver National Institute of Child Health and Human Development to the Population Research Institute at The Pennsylvania State University for Population Research Infrastructure (R24 HD41025) and Family Demography Training (T-32HD007514).

\section{References}

Achenbach, TM.; McConaughy, SH. Empirically based assessment of child and adolescent psychopathology: Practical applications. 2. Thousand Oaks, CA: Sage; 1997.

Ackard D, Neumark-Sztainer D, Story M, Perry C. Parent-child connectedness and behavioral and emotional health among adolescents. American Journal of Preventative Medicine. 2006; 30(1):59_ 66.

Arora CMJ. Defining bullying: towards a clearer general understanding and more effective intervention strategies. School Psychology International. 1996; 17:319-329.

Baldry AC, Farrington DP. Protective factors as moderators of risk factors in adolescence bullying. Social Psychology of Education. 2005; 8:263-284.

Barber, BK.; Stolz, HE.; Olsen, JA. Parental support, psychological control, and behavioral control: assessing relevance across time, culture, and method. In: Overton, WF., editor. Monographs of the Society for Research in Child Development. Vol. 70. Boston, MA: Blackwell Publishing; 2005. 
Boulton MJ, Trueman M, Chau C, Whitehand C, Amatya K. Concurrent and longitudinal links between friendship and peer victimization: implications for befriending interventions. Journal of Adolescence. 1999; 22:461-466. [PubMed: 10469510]

Bowes L, Maughan B, Caspi A, Moffitt T, Arseneault L. Families promote emotional and behavioral resilience to bullying: evidence of an environmental effect. Journal of Child Psychology and Psychiatry. 2010; 51(7):809-817. [PubMed: 20132419]

Boyce W, Torsheim T, Currie C, Zambon A. The family affluence scale as a measure of national wealth: validation of an adolescent self-report measure. Social Indicators Research. 2006; 78:473487.

Cohen S, Wills TA. Stress, social support, and the buffering hypothesis. Psychological Bulletin. 1985; 98(2):310-357. [PubMed: 3901065]

Crick NR, Grotpeter JK. Relational aggression, gender and social-psychological adjustment. Child Development. 1995; 66(3):710-722. [PubMed: 7789197]

Crick, N.; Werner, N.; Casas, J.; O’Brien, K.; Nelson, D.; Grotpeter, J.; Markon, K. Childhood Aggression and Gender: A New look at an Old Problem. In: Bernstein, D., editor. Gender and Motivation. Vol. 45. Lincoln, NE: University of Nebraska Press; 1999. p. 75-141.

Currie, C.; Roberts, C.; Morgan, A.; Smith, R.; Settertobulte, W.; Samdal, O.; Barnekow Rasmussen, V., editors. Health Policy for Children and Adolescents No.4. WHO Regional Office for Europe; Copenhagen, Denmark: 2004. Young people's health in context, health behaviour in school-aged children study: international report from the 2001/2002 survey.

Davidson L, Demaray MK. Social Support as a Moderator between Victimization and InternalizingExternalizing Distress from Bullying. School Psychology Review. 2007; 36(3):383-404.

Demo DH, Acock AC. Family structure, family process, and adolescent well-being. Journal of Research on Adolescence. 1996; 6(4):457-488.

DeVoe, J.; Murphy, C. U.S. Department of Education: National Center for Education Statistics; 2011. Student reports of bullying and cyber-bullying: results from the 2009 School Crime Supplement to the National Crime Victimization Survey. (Publication number NCES 2012314). Retrieved from http://nces.ed.gov/pubs2011/2011336.pdf, on 5/11/11

Eder, D.; Evans, CC.; Parker, S. School Talk: Gender and Adolescent Culture. New Brunswick, NJ: Rutgers University Press; 1995.

Enders CK, Bandalos DL. The Relative Performance of Full Information Maximum Likelihood Estimation for Missing Data in Structural Equation Models. Structural Equation Modeling. 2001; 8(3):430-457.

Esbensen FA, Carson DC. Consequences of Being Bullied: Results from a Longitudinal Assessment of Bullying Victimization in a Multisite Sample of American Students. Youth \& Society. 2009; 41(2):209-233.

Flegenheimer, M. Accusations of Bullying After Death of Teenager. The New York Times. 2012 Jan 3. Accessed online http://www.nytimes.com/2012/01/04/nyregion/accusations-of-bullying-afterdeath-of-staten-island-teen.html?_r=1 on 1/20/12

Gentzler AL, Contreras-Grau J, Kerns K, Weimer B. Parent-child emotional communication and children's coping in middle childhood. Social Development. 2005; 14(4):591-612.

Goodman E, Slap G, Huang B. The public health impact of socioeconomic status on adolescent depression and obesity. American Journal of Public Health. 2003; 93(11):1844-1850. [PubMed: 14600051]

Gore S, Aseltine RH, Colten ME. Gender, social-relational involvement and depression. Journal of Research on Adolescence. 1993; 3(2):101-125.

Hartos J, Power T. Mothers' awareness of their early adolescents' stressors: relation between awareness and adolescent adjustment. Journal of Early Adolescence. 1997; 17(4):371-389.

Hawker DSJ, Boulton M. Twenty years' research on peer victimization and psychosocial maladjustment: a meta-analytic review of cross-sectional studies. Journal of Child Psychology and Psychiatry. 2000; 41(4):441-455. [PubMed: 10836674]

Haynie DL, Nansel T, Eitel P, Crump AD, Saylor K, Yu K, Simons-Morton B. Bullies, victims, and bully/victims: distinct groups of at-risk youth. The Journal of Early Adolescence. 2001; 21:29-49. 
Holt MK, Espelage DL. Perceived social support among bullies, victims, and bully-victims. Journal of Youth and Adolescence. 2007; 36:984-994.

Houle J, Staff J, Mortimer JT, Uggen C, Blackstone A. The psychological impact of sexual harassment during the early occupational career. Society and Mental Health. 2011; 1(2):89-105. [PubMed: 22140650]

King V. The antecedents and consequences of adolescents' relationships with stepfathers and nonresident fathers. Journal of Marriage and the Family. 2006; 68(4):910-928. [PubMed: 18270551]

Kline, Rex. Principles and Practice of Structural Equation Modeling. 3. New York, NY: The Guilford Press; 2011.

Lamarche V, Brendgen M, Boivin M, Vitaro F, Dionne G, Perusse D. Do friends' characteristics moderate the prospective links between peer victimization and reactive $\&$ proactive aggression. Journal of Abnormal Child Psych. 2007; 35:665-680.

Leadbeater BJ, Kuperminc GP, Blatt SJ, Hertzog C. A multivariate model of gender differences in adolescents' internalizing and externalizing problems. Developmental Psychology. 1999; 35(5): 1268-1282. [PubMed: 10493653]

Lewinsohn PM, Hops H, Roberts RE, Seeley JR, Andrews JA. Adolescent psychopathology: I. prevalence and incidence of depression and other DSM-III- R disorders in high school students. Journal of Abnormal Psychology. 1993; 102(1):133-144. [PubMed: 8436689]

Lorenz FO, Conger RD, Simon RL, Whitbeck LB, Elder GH. Economic pressure and marital quality: an illustration of the method variance problem in the causal modeling of family processes. Journal of Marriage and the Family. 1991; 53:375-388.

Lui Y. Parent-child interaction and children's depression: the relationships between parent-child interaction and children's depressive symptoms in Taiwan. Journal of Adolescence. 2003; 26:447457. [PubMed: 12887933]

Masten A, Coatsworth JD. The development of competence in favorable and unfavorable environments: lessons from research on successful children. American Psychologist. 1998; 53(2): 205-220. [PubMed: 9491748]

Moore, KA.; Chalk, R.; Scarpa, J.; Vandivere, S. Family strengths: often overlooked, but real. ChildTrends Research Brief. 2002. Retrieved from http://www.childtrends.org/files/ familystrengths.pdf on $1 / 20 / 12$

Mouttapa M, Valente T, Gallaher P, Rohrbach LA, Unger JB. Social network predictors of bullying and victimization. Adolescence. 2004; 39(154):315-335. [PubMed: 15563041]

Muthén, LK.; Muthén, BO. Mplus User’s Guide. 6. Los Angeles, CA: Muthén \& Muthén; 2010.

Nansel TR, Overpeck M, Pilla RS, Ruan WJ, Simons-Morton B, Scheidt P. Bullying behaviors among US youth: prevalence and association with psychosocial adjustment. Journal of the American Medical Association. 2001; 285(16):2094-2100. [PubMed: 11311098]

Newman BM. The changing nature of the parent-adolescent relationship from early to late adolescence. Adolescence. 1989; 24(96):915-924. [PubMed: 2610039]

Olweus, D. Aggression in the Schools: Bullies and Whipping Boys. Washington, DC: Hemisphere Publishing Corporation; 1978.

Olweus, D. Victimization by peers: antecedents and long-term consequences. In: Rubins, KH.; Asendorf, JB., editors. Social Withdrawal, Inhibition, and Shyness in Childhood. Hillsdale, NJ: Erlbaum; 1992. p. 315-338.

Olweus, D. Peer harassment: a critical analysis and some important issues. In: Junonen, J.; Graham, S., editors. Peer Harassment in School: the Plight of the Vulnerable and Victimized. New York, NY: The Guilford Press; 2001. p. 3-20.

Paquette JA, Underwood MK. Gender differences in young adolescents' experiences of peer victimization: social and physical aggression. Merrill-Palmer Quarterly. 1999; 45(2):242-266.

Perry DG, Pauletti RE. Gender and adolescent development. Journal of Research on Adolescence. 2011; 21(1):61-74.

Rose AJ, Rudolph KD. A review of sex differences in peer relationship processes: potential trade-offs for the emotional and behavioral development of girls and boys. Psychological Bulletin. 2006; 132(1):98-131. [PubMed: 16435959] 
Saluja G, Iachan R, Scheidt P, Overpeck M, Sun W, Giedd J. Prevalence of and Risk factors for depressive symptoms among young adolescents. Archives of Pediatric and Adolescent Medicine. 2004; 158:760-765.

Satorra A, Bentler P. A scaled difference chi-square test statistic for moment structure analysis. Psychometrika. 2001; 66:507-512.

Smokowski, Paul R.; Kelly, Holland Kopsz. Bullying in school: an overview of types, effects, family characteristics, and interventions. Children \& Schools. 2005; 27(2):101-110.

Spriggs A, Iannotti RJ, Nansel T, Haynie D. Adolescent bullying involvement and perceived family, peer and school relations: commonalities and differences across race/ethnicity. Journal of Adolescent Health. 2007; 41:283-293. [PubMed: 17707299]

Stevens V, De Bourdeaudhuij I, Van Ooost P. Relationship of the family environment to children's involvement in bully/victim problems at school. Journal of Youth and Adolescence. 2002; 31(6): 419-428.

Wang J, Iannotti R, Nansel T. School bullying among adolescents in the United States: physical, verbal, relational, and cyber. Journal of Adolescent Health. 2009; 45:368-375. [PubMed: 19766941] 


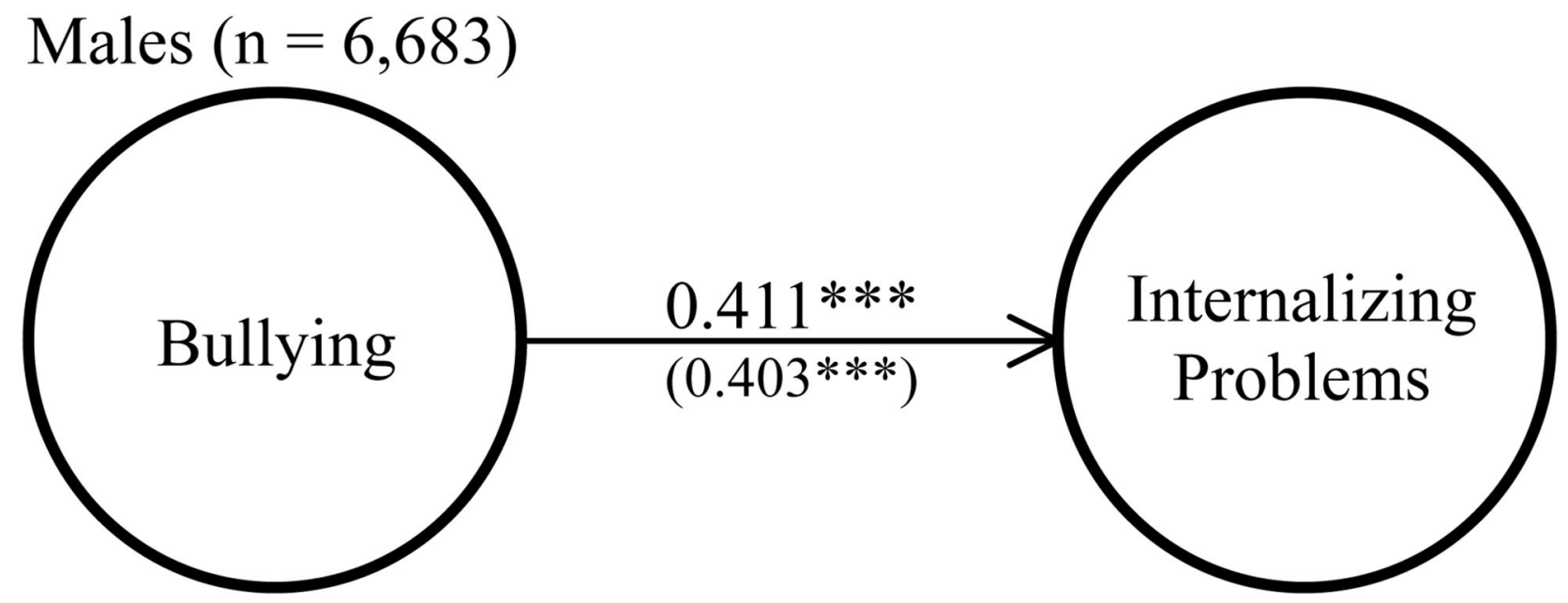

Females $(\mathrm{n}=7,356)$

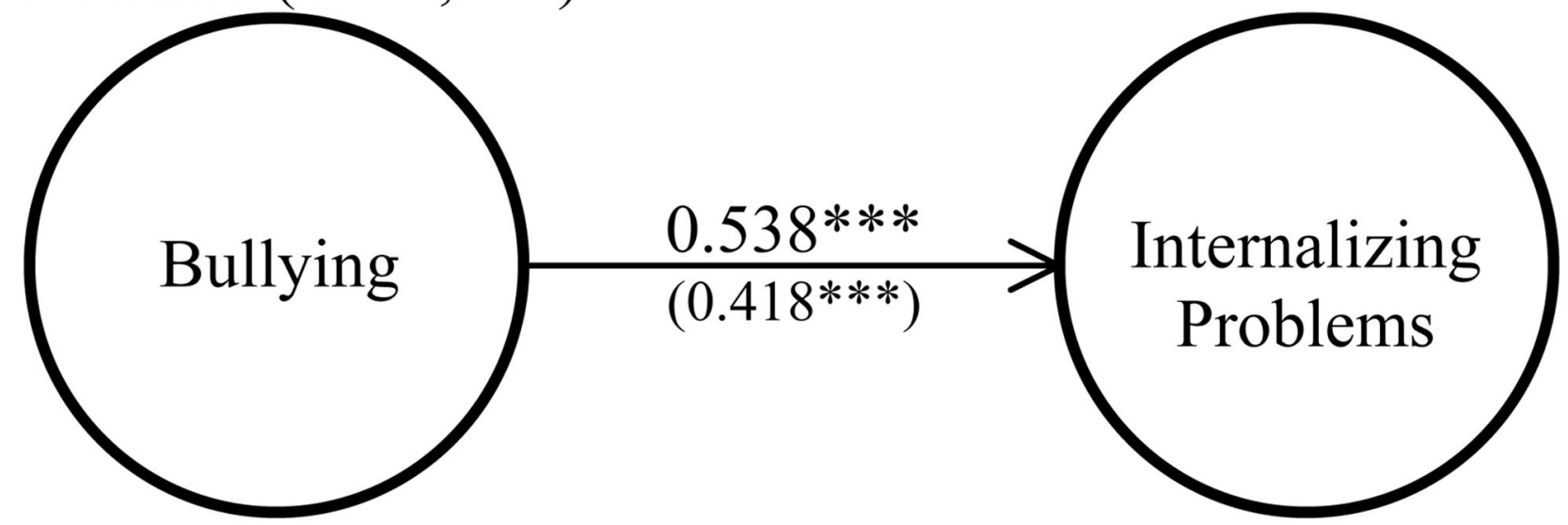

$\mathrm{CFI}=0.95 ; \mathrm{RMSEA}=0.03$

Satorra-Bentler Scaled $\chi^{2}$ Test:

17.582, $\mathrm{DF}=1, * * * \mathrm{p}<0.001$

Figure 1. Gender Differences in the Impact of Bullying on Psychosocial Maladjustment Notes: The difference between the coefficients for males and females is statistically significant at the $\mathrm{p}<0.001$ level (see text). Unstandardized coefficients are reported, standardized coefficients are in parentheses. Results are based on unweighted data; *** $\mathrm{p}<$ 0.001 Controls included in the models (age, race/ethnicity, family structure, family affluence scale, whether the respondent has at least one close friend, and the respondent's frequency of bullying others). 
Female, Low

Communication

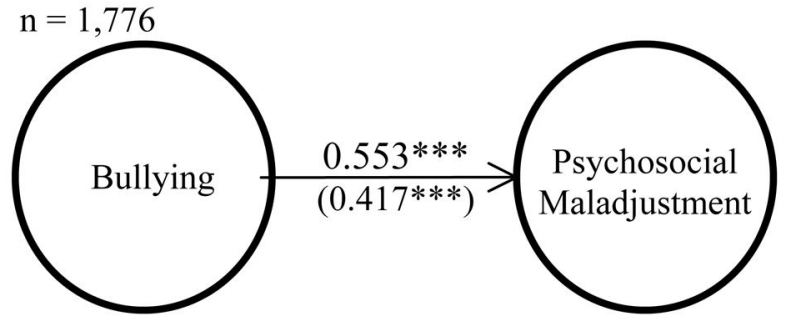

Males, Low

Communication

$\mathrm{n}=1,328$

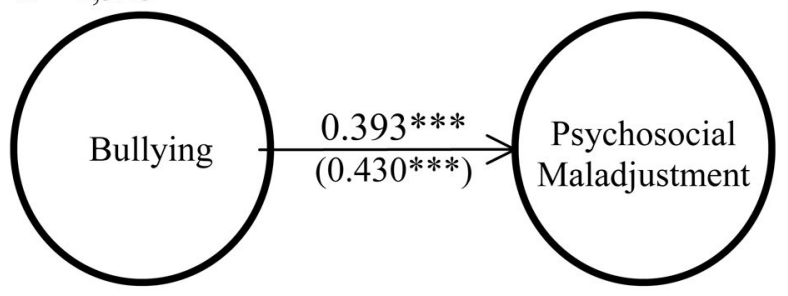

Females, High

Communication

$\mathrm{n}=5,271$

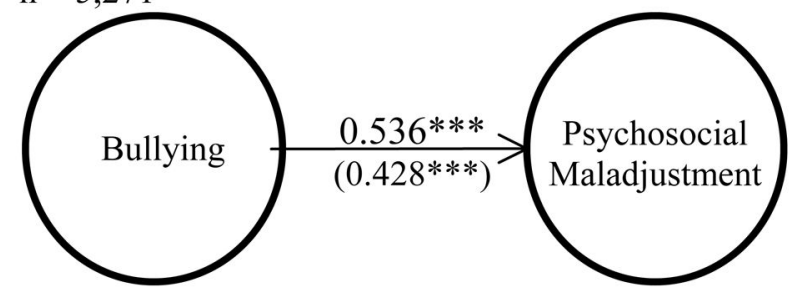

Males, High

Communication

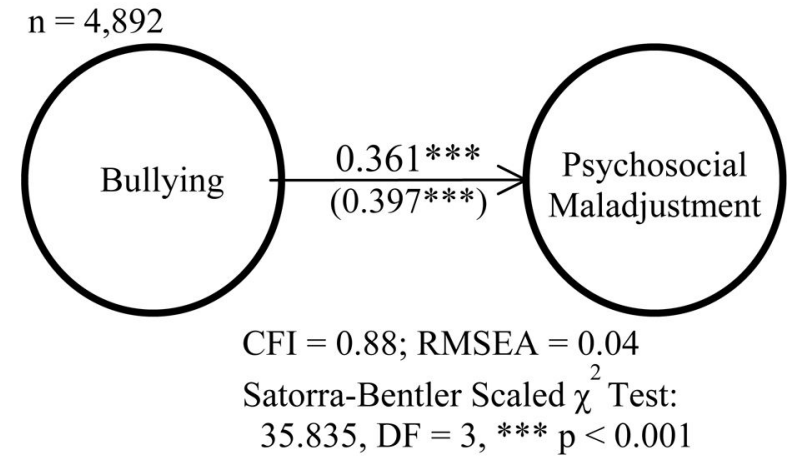

Figure 2. Multi-group Models by Gender \& Level of Parental Communication

Notes: The difference between the coefficients for the four groups is statistically significant at the $\mathrm{p}<0.001$ level (see text). Unstandardized coefficients are reported, standardized coefficients are in parentheses. Results are based on unweighted data; *** $\mathrm{p}<0.001$ Controls included in models (age, race/ethnicity, family structure, family affluence scale, isolated, bully others). 
Table 1

Prevalence of Experiencing Bullying by Sub-type and Gender (\%)

\begin{tabular}{|c|c|c|c|}
\hline & Both & Females & Males \\
\hline \multicolumn{4}{|l|}{ Physical } \\
\hline Has not experienced bullying in last few months & 86 & 92 & 80 \\
\hline Experienced bullying 1-2 times in last few months & 7 & 5 & 10 \\
\hline Experienced bullying $2-3$ times in last month & 2 & 1 & 3 \\
\hline Experienced bullying about once a week & 2 & 1 & 2 \\
\hline Experienced bullying several times a week & 3 & 1 & 5 \\
\hline \multicolumn{4}{|l|}{ Called Names } \\
\hline Has not experienced bullying in last few months & 66 & 67 & 64 \\
\hline Experienced bullying 1-2 times in last few months & 19 & 20 & 18 \\
\hline Experienced bullying 2-3 times in last month & 4 & 4 & 5 \\
\hline Experienced bullying about once a week & 4 & 3 & 4 \\
\hline Experienced bullying several times a week & 7 & 6 & 9 \\
\hline \multicolumn{4}{|l|}{ Sex Jokes } \\
\hline Has not experienced bullying in last few months & 75 & 73 & 78 \\
\hline Experienced bullying $1-2$ times in last few months & 12 & 14 & 9 \\
\hline Experienced bullying 2-3 times in last month & 4 & 4 & 3 \\
\hline Experienced bullying about once a week & 3 & 3 & 3 \\
\hline Experienced bullying several times a week & 6 & 6 & 7 \\
\hline \multicolumn{4}{|l|}{ Left Out } \\
\hline Has not experienced bullying in last few months & 73 & 72 & 74 \\
\hline Experienced bullying 1-2 times in last few months & 15 & 17 & 12 \\
\hline Experienced bullying $2-3$ times in last month & 4 & 4 & 4 \\
\hline Experienced bullying about once a week & 3 & 3 & 4 \\
\hline Experienced bullying several times a week & 5 & 4 & 6 \\
\hline \multicolumn{4}{|l|}{ Rumors } \\
\hline Has not experienced bullying in last few months & 68 & 66 & 70 \\
\hline Experienced bullying 1-2 times in last few months & 18 & 21 & 15 \\
\hline Experienced bullying $2-3$ times in last month & 5 & 5 & 5 \\
\hline Experienced bullying about once a week & 3 & 3 & 3 \\
\hline Experienced bullying several times a week & 6 & 5 & 7 \\
\hline \multicolumn{4}{|l|}{ Any form of Bullying } \\
\hline Has not experienced bullying in last few months & 46 & 43 & 48 \\
\hline Experienced bullying $1-2$ times in last few months & 26 & 29 & 23 \\
\hline Experienced bullying 2-3 times in last month & 7 & 8 & 7 \\
\hline Experienced bullying about once a week & 7 & 7 & 7 \\
\hline Experienced bullying several times a week & 14 & 13 & 15 \\
\hline
\end{tabular}

Note: Weighted results based on non-missing data.

J Fam Issues. Author manuscript; available in PMC 2016 April 01. 


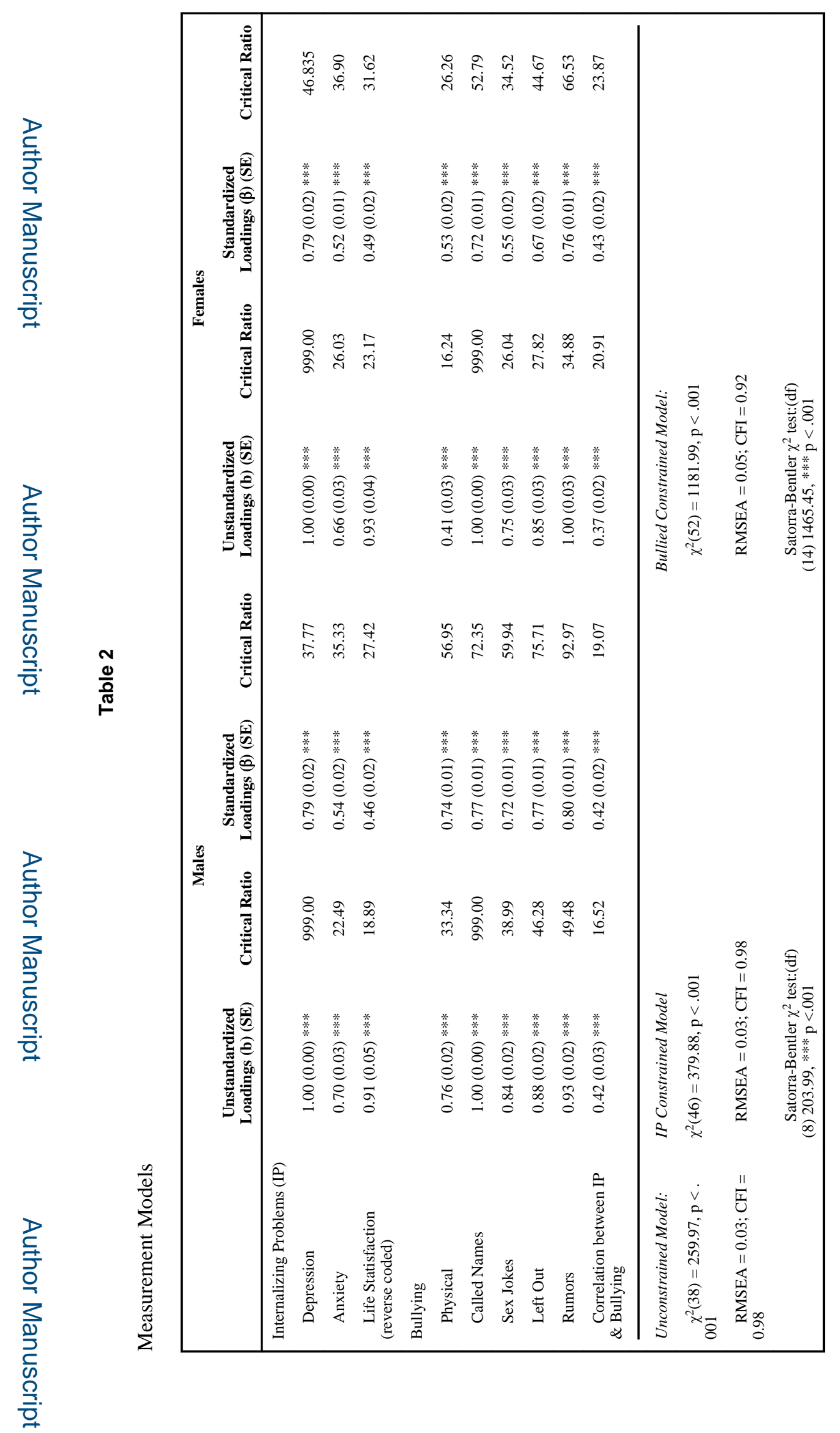

J Fam Issues. Author manuscript; available in PMC 2016 April 01. 